\title{
Experimental Evaluations of Solid-fueled Pressurized Chemical Looping Combustion-The effects of pressure, solid fuel and iron-based oxygen carriers
}

\author{
Liangyong Chen ${ }^{\mathrm{a}}$, Liang Kong ${ }^{\mathrm{a}}$, Jinhua Bao ${ }^{\mathrm{a}}$, Megan Combs ${ }^{\mathrm{a}}$, Heather S Nikolic ${ }^{\mathrm{a}}$, Zhen Fan ${ }^{\mathrm{a}}$, and Kunlei Liu ${ }^{\mathrm{a}, \mathrm{b} *}$ \\ a. Center for Applied Energy Research, University of Kentucky, 2540 Research Park Drive, Lexington, KY 40511- \\ 8410, United States \\ b. Department of Mechanical Engineering, University of Kentucky, Lexington, KY 40506, United States \\ *Corresponding author: (+1) 859257 0293; E-mail address: kunlei.liu@uky.edu
}

\begin{abstract}
Coal-based Pressurized Chemical Looping Combustion Combined Cycle (PCLC-CC) is the second generation of coal-fueled CLC plant, which possesses much higher plant efficiency and lower$\mathrm{CO}_{2}$ capture cost compare to the first generation - Coal-based CLC combined solely with steam cycle. PCLC-CC has a similar plant configuration to the Pressurized Fluidized Bed Combined Cycle (PFBC), and is composed of a PCLC Island, gas turbine, Heat Recovery Steam Generator (HRSG) and steam cycle. In the fuel reactor of PCLC Island, the metal-based oxygen carrier (OC) supplies oxygen for coal combustion and in-situ $\mathrm{CO}_{2}$ capture. The air reactor of PCLC Island, where OC is re-oxidized by air, serves as a combustion reactor to produce oxygen-depleted air of high temperature and high pressure to drive gas turbine and the followed steam cycle for large-scale power generation. This research provides an initial understanding of the complex reactions in the fuel reactor of solid-fueled PCLC Island in the pressures range of 1-6 bars. Experiments conducted in the TGA apparatus and the fixed- and fluidizedbed reactors demonstrated the effects of operational pressure, coal char reactivity and different iron-based OC's behaviors on the performances of PCLC.
\end{abstract}

Key words: Pressurized chemical looping combustion, solid fuel, iron-based oxygen carrier, gasification rate, combustion efficiency

\section{Introduction}

Chemical Looping Combustion (CLC) is an advanced technology under development to achieve efficient energy conversion of carbon fuels with in-situ $\mathrm{CO}_{2}$ capture. The CLC process is composed of two-step combustion in which oxygen carrier (OC) materials, generally metal oxides supported by inert material, provide lattice oxygen for fuel combustion in one reactor (fuel reactor, FR), and in another reactor (air reactor, AR) the oxygen-depleted OC is separately re-oxidized by air back to the full oxidized form for next cycle. Due to the separation between air and fuel, high purity $\mathrm{CO}_{2}$ stream can be recovered from the FR for sequestration. By avoiding energy intensive gas separation processes, CLC plant could potentially provide much higher efficiency than the conventional combustion technologies with $\mathrm{CO}_{2}$ capture [1].

Gaseous-fueled CLC units have been successfully demonstrated in the last ten years, with capacity ranging from $10 \mathrm{~kW}_{\text {th }}$ to the $140 \mathrm{~kW}_{\text {th }}$ [1-4]. These CLC units are usually configured with two interconnected fluidized-bed reactors which operated at atmospheric pressure. Recently, the coal-fueled CLC has become attractive due to the extensive availability and low cost of coal [5-8]. Research also demonstrated the feasibility of using pet-coke, solid wastes and biomass for CLC [9-11]. Solid fuel can be utilized via in-situ gasification chemical looping combustion (iG-CLC), where solid fuel is introduced directly to the FR. This allows solid fuel gasification and syngas combustion with metal oxide to occur simultaneously. The major advantages of iG-CLC are the elimination of air separation unit and extra 

gasification inhibitors $\left(\mathrm{CO} / \mathrm{H}_{2}\right)$ in the FR [12-13]. Currently, a number of iG-CLC facilities (ambient pressure) with thermal inputs ranging from $1 \mathrm{~kW}_{\text {th }}$ to $3 \mathrm{MW}_{\text {th }}$ have been constructed worldwide [1, 14-17]. Among the OCs used, low-cost iron-based OCs are the preferred materials for solid fuel combustion. Circulating Fluidized Bed (CFB) or Bubbling Fluidized Bed (BFB) is commonly adopted as the fuel reactor. Today, the largest solid-fueled CLC unit is Alstom's $3 \mathrm{MW}_{\text {th }}$ system in Windsor, USA, using Cabased OCs [15]. $1 \mathrm{MW}_{\text {th }}$ CLC facility using hard coal and iron-based OCs has been successfully demonstrated and operated in a continuous model without external heat sources [18]. A design of a 455 MWe CLC power plant with solid fuel has been developed within the project ENCAP [19]. Recently, an engineering design for the coal-fueled CLC boiler was also performed at a commercial-scale $\left(1,000 \mathrm{MW}_{\mathrm{th}}\right)$ with ilmenite OC as circulating material for fuel combustion [20].

There are still significant challenges with the performance and the cost of the solid-fueled CLC. Several issues contribute to these challenges, including OC's cost and efficiency, kinetics, reactor configuration, and solid handling. The present cost for OC makeup and disposal are very close to that of fuels even the low-cost iron-based OCs are used [21]. Both solid circulating between the two reactors and char-OC separation process (either as a stand-alone process or as a part of reducer), need to process very large amount of solids. Presently, the FR is operated at relatively low temperature, where coal gasification is very slow. As demonstrated by the solid-fueled CLC facilities worldwide, the FR off-gas contained a substantial amount of unconverted gas $\left(\mathrm{H}_{2}\right.$ and $\left.\mathrm{CO}\right)$. Furthermore, the plant efficiency of the present CLC configuration (the first generation) is not as high as anticipated (35.1\% for the iron-based CLC plant and $32.6 \%$ for the Ca-based CLC plant [21]).

At University of Kentucky, Center for Applied Energy Research (UKy-CAER), a second generation of coal-fueled CLC plant has been proposed to significantly improve plant efficiency and $\mathrm{CO}_{2}$ capture. The second generation system has a plant configuration similar to gaseous-fueled PCLC reported by Hamers [22] or Pressurized Fluidized Bed Combined Cycle. The direct coal-fueled PCLC unit serves as a combustor to generate a flue gas stream of high temperature and high pressure. This flue gas is used to drive a gas turbine and the following steam cycle for large-scale power generation. After water condensation and heat recovery steps, $\mathrm{CO}_{2}$ stream from the FR is compressed for sequestration. Costeffective iron-based OCs from solid waste or natural ore are selected to increase operational temperature and to reduce operational costs. The major driving forces for the development of the second generation CLC system are the higher plant efficiency and low costs of electricity and $\mathrm{CO}_{2}$ capture. Our thermodynamic analysis [23] predicted that the second generation system at the scale of $550 \mathrm{MWe}$ could provide more than $90 \% \mathrm{CO}_{2}$ capture, greater than $95 \% \mathrm{CO}_{2}$ purity, and a net plant efficiency of more than $44.5 \%$ (LHV) with $\mathrm{CO}_{2}$ pressurized to 2,215 psi. A similar PCLC process was proposed by Southeast University (SEU), China, but no calculated plant efficiency was provided [24]. A $100 \mathrm{~kW}_{\text {th }}$ PCLC unit has been demonstrated using iron ore and coal by SEU [25].

Although the second generation of the solid-fueled PCLC is promising, almost no test data and experience are available to initial operation conditions and design parameter selection, and further to project plant performance and cost. Very little information has been reported on kinetics of OCs at elevated pressure [26-30]. However, these data were collected for the understanding of the main characteristics of the gaseous fueled-CLC. The goal of this research was to gain an initial understanding of the reactions in the FR of the solid-fueled PCLC, and collect essential information to evaluate performance and design parameter selection. Experiments were conducted at pressures ranging from 1-6 

iron-based OCs. Two red mud OCs (RM OC) and ilmenite ore were selected as OC materials. RM OC was developed by UKy-CAER from Bauxite residuals of aluminum industry, which has been identified as a cost-effective OC for the coal-fueled CLC. The flow regime of FR was designed at a bubbling fluidized bed for both OCs and coal char. For the sake of simplicity, coal char and steam were used as fuel and gasification agent, respectively. Both $\mathrm{H}_{2} \mathrm{O}$ and $\mathrm{CO}_{2}$ have been proposed as gasification agents for the solid-fueled CLC. $\mathrm{CO}_{2}$ can be fed by recirculating a fraction of the product gas of the FR. Thus, to some extent the steam requirement and the energy penalty for steam generation can be reduced. The effect of using $\mathrm{CO}_{2}$ with steam on the solid-fueled CLC has been validated by Ana Cuadrat [12], showing that the increase of $\mathrm{CO}_{2}$ fraction in gas mixture would significantly drop the gasification rate and combustion efficiency.

\section{Experimental}

\subsection{Materials}

Three iron-based OCs were used in this research, including activated ilmenite ore and two RM OCs. Ilmenite ore has been identified as a low-cost OC, and its behaviors in both gaseous- and solid-fueled CLC processes have been reported [31-33]. The raw ilmenite ore was primarily composed of $\mathrm{FeTiO}_{3}$, $\mathrm{TiO}_{2}$, and a small amount of $\mathrm{Fe}_{2} \mathrm{O}_{3}$. As a pretreatment, the ore was crushed into 125-355 $\mu \mathrm{m}$ particles, stabilized in air at $950{ }^{\circ} \mathrm{C}$ for 24 hours, and activated by 10 redox cycles $\left(20 \% \mathrm{CO}\right.$ in $\mathrm{N}_{2}$ gas for 15 min oxidation, and diluted air for regeneration) in a fluidized bed reactor. The two RM OCs, S-RM OC and ARM OC, were prepared from two different Bauxite residuals of aluminum industry by lab-scale freezegranulation. The detail methods can be found in our previous study [34]. Both RM OCs were calcinated at $1,150{ }^{\circ} \mathrm{C}$ for 6 hours to obtain the proper particle morphology and mechanical strength. These calcinated particles in the range of $125-355 \mu \mathrm{m}$ were collected for experimentation.

Table 1 summarizes the chemical composition and physical properties of these OCs tested. SEM images of the fresh OC particles are included in the supporting information (S-Fig. 1). In the baseline experiment, fused $\mathrm{Al}_{2} \mathrm{O}_{3}$ particles $(125-355 \mu \mathrm{m})$ were used as bed materials for coal char external gasification, and its physical properties are listed in Table 1. The XRD patterns, presented in Fig. 1, shows that the active content of two RM OCs are $\mathrm{Fe}_{2} \mathrm{O}_{3}$, and $\mathrm{Ca}-\mathrm{Al}-\mathrm{O}$, or Na-Al-Si-OC composite functions as structural supports. Previous research [34] showed that the active content (free $\mathrm{Fe}_{2} \mathrm{O}_{3}$ phase) in RM OCs can be completely reduced to metallic iron by dry syngas, and all iron-containing phases involved during the reduction and regeneration, i.e. $\mathrm{Fe}_{2} \mathrm{O}_{3}, \mathrm{Fe}_{3} \mathrm{O}_{4}, \mathrm{FeO}$ and $\mathrm{Fe}$, did not react with the support material to form a new spinel phase. Therefore, the unique structure of RM OCs ensures the reaction with coal-derived syngas will be the reduction of free $\mathrm{Fe}_{2} \mathrm{O}_{3}$ to $\mathrm{Fe}_{3} \mathrm{O}_{4}, \mathrm{FeO}$ and further to metallic iron. The crystalline phases identified in the activated ilmenite $\mathrm{OC}$ include $\mathrm{Fe}_{2} \mathrm{TiO}_{5}, \mathrm{TiO}_{2}$ and a small amount of $\mathrm{Fe}_{2} \mathrm{O}_{3}$. The $\mathrm{Fe}_{2} \mathrm{TiO}_{5}$ and $\mathrm{Fe}_{2} \mathrm{O}_{3}$ phases are lattice oxygen donors for fuel combustion in CLC process.

Three different coal chars, prepared from Power River Basin (PRB), Eastern Kentucky and Western Kentucky coals (EKY and WKY), were used as solid fuels. PRB char was produced using a fixed bed reactor in hot $\mathrm{N}_{2}$ flow stream at $800{ }^{\circ} \mathrm{C}$ for 20 minutes. The bulk samples were crushed and sieved to 180 $355 \mu \mathrm{m}$ particles for experimentation. The other two chars were prepared following the same procedures, but the pretreatment temperature was $700{ }^{\circ} \mathrm{C}$. The proximate and ultimate analyses of three coal chars are presented in Table 2. 


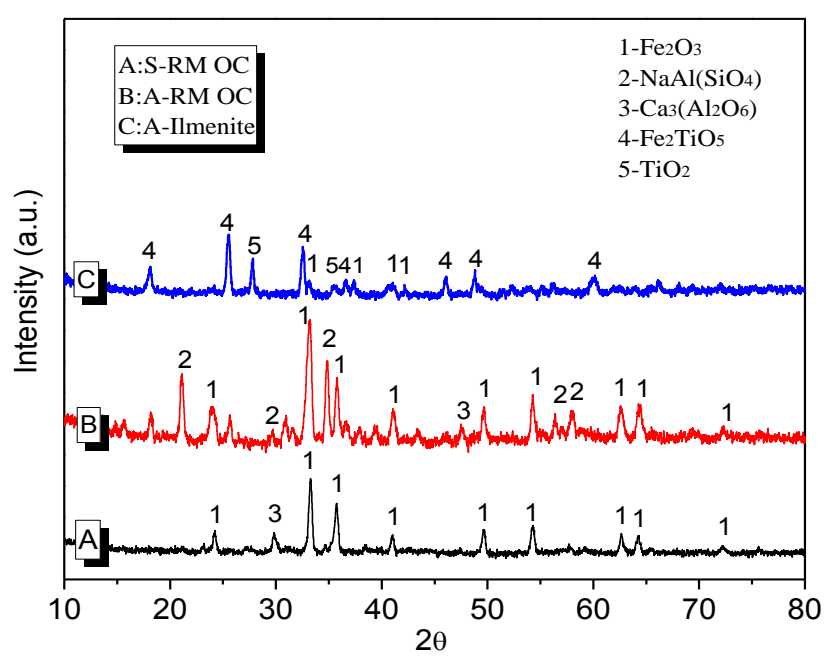

Fig. 1 XRD patters of different iron-based OCs

Table 1 Chemical composition and physical properties of OCs

\begin{tabular}{lccccc}
\hline & & $\mathrm{S}-\mathrm{RM}$ & $\mathrm{A}-\mathrm{RM}$ & $\mathrm{A}-$-Ilmenite & $\mathrm{Al}_{2} \mathrm{O}_{3}$ \\
\hline Composition & $\mathrm{Fe}_{2} \mathrm{O}_{3}$ & 48.35 & 45.47 & 52.46 & - \\
& $\mathrm{SiO}_{2}$ & 11.68 & 9.69 & 5.4 & - \\
& $\mathrm{Al}_{2} \mathrm{O}_{3}$ & 17.07 & 21.76 & 4.32 & 99.9 \\
& $\mathrm{TiO}_{2}$ & 6.19 & 8.95 & 33.04 & - \\
& $\mathrm{CaO}$ & 12.77 & 5.08 & 0.99 & - \\
& $\mathrm{MgO}$ & 0.48 & 0.27 & 3.26 & - \\
& $\mathrm{Na} 2 \mathrm{O}$ & 2.31 & 8.07 & - & - \\
& $\mathrm{K}_{2} \mathrm{O}$ & 0.22 & 0.09 & - & - \\
& $\mathrm{Balance}$ & 0.93 & 0.62 & 0.53 & - \\
\cline { 2 - 6 } Particle Density & $\mathrm{g} / \mathrm{cm}^{3}$ & 3.53 & 3.64 & 4.09 & 3.96 \\
Bulk Density & $\mathrm{g} / \mathrm{cm}^{3}$ & 1.30 & 1.15 & 2.20 & 1.45 \\
$d_{50}$ & $\mu \mathrm{m}$ & 254 & 266 & 310 & 245 \\
Sphericity for cal. & & 0.9 & 0.9 & 0.55 & 0.55 \\
Crushing Strength & $\mathrm{N}$ & 2.06 & 2.26 & 3.52 & - \\
BET Surface Area & $\mathrm{m}^{2} / \mathrm{g}$ & 0.246 & 0.311 & 0.284 & - \\
\hline
\end{tabular}

Table 2 Proximate and ultimate analyses of coal char

\begin{tabular}{lcccc}
\hline & & PRB & EKY & WKY \\
\hline Proximate Analysis & wt.\% & & & \\
Ash & & 16.28 & 15.92 & 14.72 \\
Volatiles & & 3.13 & 4.33 & 4.34 \\
Fixed carbon & 80.59 & 79.39 & 79.38 \\
\hline Ultimate Analysis & wt.\% & & & \\
$\mathrm{C}$ & & 77.4 & 78.26 & 76.74 \\
$\mathrm{H}$ & & 1.38 & 1.67 & 1.84 \\
$\mathrm{O}$ & & 1.52 & 1.38 & 2.55 \\
$\mathrm{~N}$ & & 1.72 & 1.75 & 1.67 \\
$\mathrm{~S}$ & & 1.70 & 1.02 & 2.48 \\
\hline Heating Value & $\mathrm{MJ} / \mathrm{kg}$ & 27.6 & 28.4 & 27.9 \\
\hline Particle Density & $\mathrm{g} / \mathrm{cm}^{3}$ & 1.24 & 1.19 & 1.12 \\
\hline
\end{tabular}




\subsection{Experiment setup and test procedure}

\subsubsection{PCLC experiment}

A fluidized bed system was used to perform the experiment of coal char-fueled PCLC. It consists of a fluidized-bed reactor, gas feeding setup, flue gas cleaning system, gas analysis system, and data acquisition system. The general layout of the fluidized bed system can be found in the previous study [35], but modification was made to adapt the system for elevated pressure operation. The fluidized-bed reactor was fabricated from stainless steel pipe (SS 310), $38 \mathrm{~mm}$ ID, 6.25 wall thickness and $850 \mathrm{~mm}$ height. An electric furnace was used to heat the heating zone (600 mm length). A micro-porous metal plate, fixed at $200 \mathrm{~mm}$ from the bottom of heating zone, was used as sample holder and gas distributor. The reactor was equipped with thermal couples and a pressure transducer to measure the bed temperature and pressure drop across the gas distributor and bed material. The gas feeding setup was equipped with different mass flow controllers for $\mathrm{N}_{2}, \mathrm{CO}$ and air. To feed an accurate amount of steam to the reactor, a dual-piston pump (P-1100, Chrom Tech. Inc.) and steam generator were used in the upstream of the reactor. The deionized water was pumped into steam generator, and subsequently vaporized and mixed with other feeding gas. The feeding gas mixture was preheated to $600{ }^{\circ} \mathrm{C}$ before entering the bottom of the reactor. The coal char was fed by a tube inserted from the top of reactor. The tube tip was $30 \mathrm{~mm}$ height above the gas distributor. So coal char could be fed into the center of the hot bed materials at the beginning of experiment. The outlet gas of the reactor passed through a cyclone, high temperature filter, cooler, and moisture trap in sequence to remove fine particles and condensate. During experiments, a needle valve was used to limit outlet gas flow and maintain the desired pressure. The dry outlet gas was continuously analyzed by a multi-gas analyzer (Rosemount, $\mathrm{X}$-stream). The gas concentration profiles of $\mathrm{O}_{2}, \mathrm{CH}_{4}, \mathrm{CO}$, $\mathrm{CO}_{2}$, and $\mathrm{H}_{2}$ along with the pressure drop, temperatures, and flow rates were recorded by the data acquisition system.

All CLC experiments were performed at $950{ }^{\circ} \mathrm{C} .1$ bar, 2 bars, 4 bars and 6 bars (absolute pressure) were adopted to investigate the effects of operational pressure. During each experiment, OC samples were preloaded in the reactor, and then heated in a pure $\mathrm{N}_{2}$ stream. When the temperature was stabilized at $950{ }^{\circ} \mathrm{C}$, the fluidization gas was switched to a stream of $50 \%$ steam balanced with $\mathrm{N}_{2}$. When the system pressure was regulated at the desired value, the bed materials were exposed to reduction or oxidation condition. During the reduction period, char was fed into the reactor through the solid feeding system. Following the reduction step, a stream of $\mathrm{N}_{2}$ was introduced for 2-3 min to allow the system purged. During the oxidation step, the reduced OC particles and residual carbon were exposed to diluted air $\left(10 \% \mathrm{O}_{2}\right)$. The performing of oxidation step was to close the chemical loop, and to calculate the mass balance of carbon and oxygen elements. External gasification experiments were performed in order to determine the reactivity of coal char (PRB, EKY and WKY) at various pressures, which was used as the baseline to evaluate the PCLC's performance. The testing procedure was the same as that of PCLC experiments, except that the bed materials were replaced by fused $\mathrm{Al}_{2} \mathrm{O}_{3}$ particles. All experiments were repeated at least once to ensure high accuracy and repeatability.

The loading of OC sample used for each CLC experiment was $150 \mathrm{~g}$, which gave a static bed height of approximate $100 \mathrm{~mm}$ for each of the OCs except for ilmenite due to its high bulk density. For the experiments using ilmenite $\mathrm{OC}, 150 \mathrm{~g}$ ilmenite $\mathrm{OC}$ mixed with $60 \mathrm{~g}$ fused $\mathrm{Al}_{2} \mathrm{O}_{3}$ particles were used to achieve a $100 \mathrm{~mm}$ static bed height. The experiment was designed to ensure that the flow regime of solid particles was almost the same for each of tests. Reactions in the FR involved two solid particles that possessed different fluidizing characteristics. The iron-based OCs in this study were considered Group B particle, while the coal chars were Group A or AB particle, according to the Geldart classification [36]. Solid particles are more mobile at higher operational pressure at a given superficial velocity of fluidizing 
gas [36]. To avoid segregation of coal char particles from the bed materials, the experiments were designed at a slow bubbling fluidization regime for OC particles and a slightly more vigorous fluidization regime for coal char particles. The amount of feeding gas for fluidization were enlarged linearly with operational pressure, i.e. $1.0 \mathrm{~g}$ steam and $1.35 \mathrm{NL} / \mathrm{min} \mathrm{N}_{2}$ for the operation at 1 bar, which was increased to $6.0 \mathrm{~g}$ steam plus $8.1 \mathrm{NL} / \mathrm{min} \mathrm{N}_{2}$ for the operation at 6 bars. This arrangement ensured the superficial velocity $\left(U_{\mathrm{o}}\right)$ in the FR was fixed at $0.165 \mathrm{~m} / \mathrm{s}$ at $950{ }^{\circ} \mathrm{C}$ for different operational pressure. This means that $\mathrm{OC}$ particles were bathed with an approximate gas velocity for different operational pressure. Fig. 2 illustrates the flow regime in the CLC experiments of various pressures. The increase of pressure from 1 to 6 bars does not impact the flow regime nor increase char segregation. The superficial velocity was approximate 3.0 times of the minimum fluidizing velocity $\left(U_{\mathrm{mf}}\right)$ of different OC particles, and 8.0 times of the $U_{\mathrm{mf}}$ of coal char particles. At 6 bars, the calculated terminal velocity of the coal char particles showed an observable decrease. However, the value of $U_{\mathrm{o}}$ at 6 bars was much lower than $U_{\mathrm{t}}$ of coal char particles. So the carryover of char particles from the bed was estimated to be low.

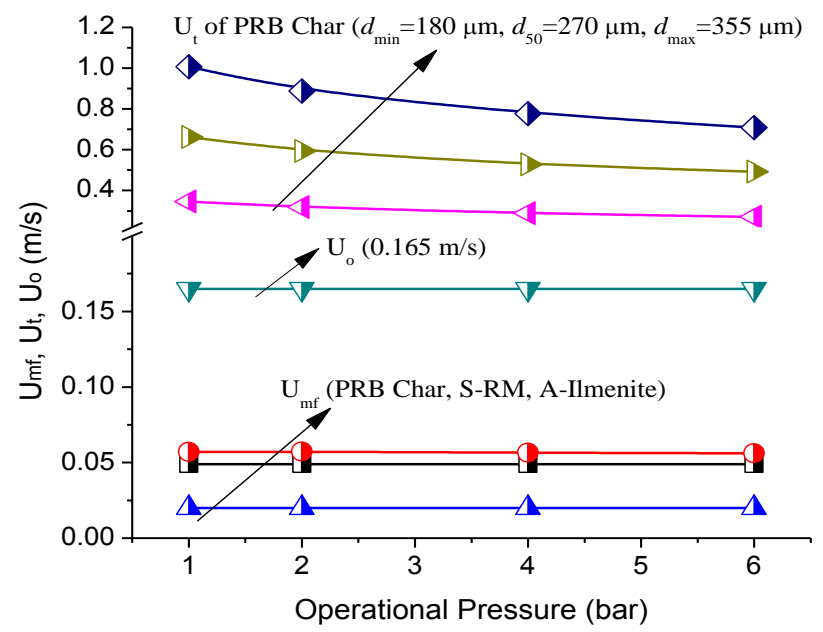

Fig. 2. Calculated minimum velocity $\left(U_{\mathrm{mf}}\right)$, terminal velocity $\left(U_{\mathrm{t}}\right)$ and superficial velocity $\left(U_{\mathrm{o}}\right)$ of different solid particles involved in the PCLC experiments $\left(U_{\mathrm{mf}}\right.$ and $U_{\mathrm{t}}$ are calculated according the methods given by Levenspiel K. [36], $d_{\min }, d_{\max }$ and $d_{50}$ are the diameter of the smallest, largest, and median PRB coal char particles, respectively)

\subsubsection{TGA and Fixed bed experiments}

The oxygen carrier reactivity and selectivity are important in the conversions of solid fuel and intermediate syngas in the FR. Two performances were pre-determined in a thermo-gravimetric analyzer (TGA, Netzsch STA 449 F3 Jupiter) and a fixed-bed reactor, respectively. A mixing gas of CO and steam was used to generate wet syngas containing $\mathrm{CO}, \mathrm{H}_{2}, \mathrm{H}_{2} \mathrm{O}$ and $\mathrm{CO}_{2}$. These gases are essential components bathing OC particles in a real solid-fueled CLC process. Furthermore, it is important that the presence of $\mathrm{H}_{2} \mathrm{O}$ significantly retards the lattice oxygen transport from OC particles to gaseous fuels, depending on OC material and the concentration of steam used.

The TGA apparatus is equipped with a steam generator that allows the OC reduction to be tested with wet syngas of variable steam concentration. The feeding of reducing gas (CO) and Ar were operated by mass flow controllers. For each test, approximately $50 \mathrm{mg}$ OC sample was loaded in a crucible, and heated to $950{ }^{\circ} \mathrm{C}$. Once the temperature and balance were stabilized, the OC sample was exposed to the stream of 
reducing gas. Because the comprehensive atmosphere surrounding OC particle always changes with the proceeding of coal gasification, the OC reduction behavior in the FR cannot be quantitatively determined. The arrangement of the TGA experiments was trying to reflect the environments of the FR at different pressures. The $\mathrm{OC}$ reactivity was tested at three different wet syngas compositions. The ratio of $\mathrm{H}_{2} \mathrm{O}$ to $\mathrm{CO}$ remained at 2:1, and the volume fraction of $\mathrm{CO}$ were $5 \%, 10 \%$ and $15 \%$, respectively. Accordingly, the steam partial pressures were $10 \%, 20 \%$, and $30 \%$. For comparison, the OC reactivity was also tested using $15 \% \mathrm{CO}$ balanced with Ar. The total flow rate of the feed gas was equivalent to $300 \mathrm{~mL} / \mathrm{min}$ (standard conditions) during all experiments.

The selectivity of OCs was evaluated at $950{ }^{\circ} \mathrm{C}$ in the fluidized bed facility but in a fixed-bed mode. The effects of pressure were investigated at 1 bar, 2 bars, 4 bars and 6 bars, respectively. During reduction, the syngas was fed from the top of reactor, and the product gases were led out of the reactor at the bottom for analysis. The reduction of OC continued until the concentrations of $\mathrm{CO}$ or $\mathrm{H}_{2}$ in existing gas increased rapidly. After the reduction period, the reactor was purged with $\mathrm{N}_{2}(3.0 \mathrm{NL} / \mathrm{min})$ for 2.0-3.0 min, and then fed with diluted air $\left(10 \% \mathrm{O}_{2}\right)$ for OC regeneration. For each experiment, the fixed-bed height was set at 0.26-0.27 m. So sample loading was $400 \mathrm{~g}$ for RM OCs, or $400 \mathrm{~g}$ ilmenite OC mixed with $160 \mathrm{~g}$ fused $\mathrm{Al}_{2} \mathrm{O}_{3}$ particles. For experiments at $1 \mathrm{bar}$, the simulated wet syngas contained $1.1 \mathrm{~g}$ steam $/ \mathrm{min}, 1.5$ $\mathrm{NL} / \mathrm{min} \mathrm{CO}$, and $1.5 \mathrm{NL} / \mathrm{min} \mathrm{N}_{2}$. At elevated pressure, the volume of feed gas (for each composite) was increased linearly with operational pressure. So these experiments allowed the effect of pressure to be investigated at the same superficial gas velocity $\left(0.27 \mathrm{~m} / \mathrm{s}\right.$ at $\left.950{ }^{\circ} \mathrm{C}\right)$. At the top of reactor, the feed gases composition was a 1:1:1 ratio of $\mathrm{CO}: \mathrm{H}_{2} \mathrm{O}: \mathrm{N}_{2}$.

\subsection{Data evaluation}

Fig. 3 illustrates the complex reaction system in the FR evaluated in this study. The major chemical reactions in the FR are char gasification, OC reduction and Water-Gas-Shift Reaction (WGSR). Coal char is first gasified by steam into syngas. Meanwhile, the reducing components are burnt by sufficient amount of iron-based OCs surrounding the coal char particles and generate $\mathrm{CO}_{2}$ and $\mathrm{H}_{2} \mathrm{O}$. A certain amount of $\mathrm{CO}$ or $\mathrm{H}_{2}$ remains in the $\mathrm{CO}_{2} / \mathrm{H}_{2} \mathrm{O}$ stream, depending on thermodynamic limitation and $\mathrm{OC}$ reactivity. Char gasification rate is improved as the inhibitions from $\mathrm{CO}$ and $\mathrm{H}_{2}$ are lowered. Steam serves as both a fluidization and gasification agent, and simultaneously inhibits lattice oxygen transfer for intermediate syngas combustion [34]. The homogeneous WGSR, catalyzed or non-catalyzed by iron-based OCs, influences the composition of the final gas products. Because the reaction between the two solids (coal char and OCs) occurs via the phase transfer of intermediate gas, the fluidization behavior and mass transfer process of the bed zone also influence the performance of the FR. For this study, OC reduction proceeds according to the following reverse reactions

For RM OCs

$$
\begin{gathered}
3 \mathrm{Fe}_{2} \mathrm{O}_{3}+\mathrm{H}_{2} \leftrightarrow 2 \mathrm{Fe}_{3} \mathrm{O}_{4}+\mathrm{H}_{2} \mathrm{O} \\
3 \mathrm{Fe}_{2} \mathrm{O}_{3}+\mathrm{CO} \leftrightarrow 2 \mathrm{Fe}_{3} \mathrm{O}_{4}+\mathrm{CO}_{2}
\end{gathered}
$$

For ilmenite OC

$$
\begin{gathered}
\mathrm{Fe}_{2} \mathrm{TiO}_{5}+\mathrm{TiO}_{2}+\mathrm{H}_{2} \leftrightarrow 2 \mathrm{FeTiO}_{3}+\mathrm{H}_{2} \mathrm{O} \\
\mathrm{Fe}_{2} \mathrm{TiO}_{5}+\mathrm{TiO}_{2}+\mathrm{CO} \leftrightarrow 2 \mathrm{FeTiO}_{3}+\mathrm{CO}_{2}
\end{gathered}
$$

The instantaneous rate of carbon conversion, $r_{\mathrm{c}}$ is used to evaluate the in-situ gasification of the solidfueled CLC 
Here $x_{\mathrm{c}}$ is the carbon conversion obtained from the total carbon converted to gas at time of $t$

$$
x_{c}=\frac{m_{c}(t)}{m_{t o t}}
$$

where $m_{t o t}$ is the mass of carbon in coal char introduced to the FR at the beginning of test, $m_{c}(t)$ is the mass of carbon in coal char that has been converted to gas phase at time of $t$.

The instantaneous conversion rate is applied to calculate the combustion efficiency of intermediate syngas that can be oxidized by OCs [13]

$$
\eta_{s y n}=1-\frac{0.5 f_{C O}+0.5 f_{\mathrm{H}_{2}}}{f_{\mathrm{CO}_{2}}+0.5 f_{\mathrm{CO}}+0.5 f_{\mathrm{H}_{2}}}
$$

Here $f_{\mathrm{i}}$ is the volumetric fractions of $i$ gas component.

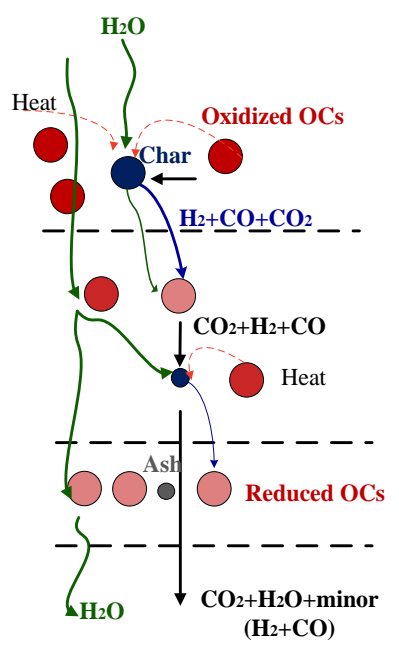

Fig. 3 Chemical reactions involved in the Fuel Reactor

The instantaneous conversion rate, $r_{\mathrm{OC}}$ is used to evaluate OC's reactivity in the TGA experiments. It is defined as the normalized OC conversion with respect to the amount of residual active content at time of $t$. It is calculated using Eq. (5) with the replacement of $x_{\mathrm{c}}$ by OC conversion, $X_{\mathrm{OC}}$. Here $X_{\mathrm{OC}}$ is calculated by

$$
X_{\mathrm{OC}}=\frac{m_{\mathrm{o}}-m_{\mathrm{oc}}(t)}{\alpha R_{\mathrm{o}} m_{\mathrm{o}}}
$$

Where $m_{\mathrm{o}}$ is the total mass of the OCs (full oxidized form) at the beginning of experiment, $m_{\mathrm{oc}}(t)$ is the mass of OCs at time of $t$ during reaction, $\alpha$ is the mass fraction of active content in the OCs. $R_{\mathrm{o}}$ is oxygen transport capacity of different redox pairs, being 0.034 for $\mathrm{Fe}_{2} \mathrm{O}_{3} / \mathrm{Fe}_{3} \mathrm{O}_{4}$ and 0.05 for $\mathrm{Fe}_{2} \mathrm{TiO}_{5} / \mathrm{FeTiO}_{3}$.

The WGSR occurs in the bed and free board zones of the FR. This reaction will try to shift the gas components toward equilibrium condition. However, the final composition of the flue gas depends on the rate of this reaction. The metal-based OCs have potential to strongly catalyze the WGSR, and can influence the selection of the fuel gas recovery process if needed. The catalytic function of iron-based OCs for the WGSR in CLC experiments were evaluated via the quotient of reaction, $J$, that describes the extent of the WGSR as it approaches equilibrium under the experimental conditions. 
where $P_{\mathrm{i}}$ is the integral partial pressure of the syngas component at the outlet of the reactor (before steam is removed). It is calculated by integrating the mole flow rate of $i$ gas components over the reduction period.

The OC selectivity $\left(S_{\text {syn }}\right)$ is used to manifest the adequate ability of the OC to convert syngas to $\mathrm{CO}_{2}$ and $\mathrm{H}_{2} \mathrm{O}$. From the gas concentration profiles of the exit gas from the fixed-bed reactor (dry-based), $S_{\text {syn }}$ can be determined using Eq. (7).

\section{Results and Discussion}

\subsection{Reactivity of oxygen carrier with wet syngas at different partial pressures}

The effect of $\mathrm{CO}$ partial pressure on OC's reactivity was investigated at $\mathrm{CO}$ concentrations of 5\%, 10\% and $15 \%$. During experiments, the $\mathrm{H}_{2} \mathrm{O} / \mathrm{CO}$ ratio of 2:1 in the feed gas were maintained. The TGA data profiles for different OCs are presented in Fig. 4 (a)-(c). For RM OCs, the mass profiles using different wet syngas were consistent with one another during the early reduction stage. After a certain point, the reduction rate slowed and became syngas-dependent. The reduction of ilmenite OCs was considerably slower than RM OCs, and was strongly syngas-dependent shortly after the reduction began.

Fig. 5 compares the reduction reactivity of different OCs with and without steam in the reducing gas. In Fig. 5 (a), $X_{O C}$ vs. time curves were calculated using Eq. (8) from the TGA profiles shown in Fig. 4. In Fig. 5 (b), $X_{\mathrm{OC}}$ vs. time curves were obtained from the TGA experiments with the dry reducing gas (15\% $\mathrm{CO}$ ) for the same OCs. For RM OCs, a value of $X_{\mathrm{OC}}$ higher than 1.0 was reached during experiments as the active content $\left(\mathrm{Fe}_{2} \mathrm{O}_{3}\right)$ was reduced beyond $\mathrm{Fe}_{3} \mathrm{O}_{4}$. However, the value of $X_{\mathrm{OC}}>1.0$ was not shown because only the reduction of $\mathrm{Fe}_{2} \mathrm{O}_{3}$ to $\mathrm{Fe}_{3} \mathrm{O}_{4}$ is of interest for industrial application. As shown in Fig. 5 (b), with the absence of steam in the reducing gas, the two RM OCs behaved similarly as $X_{\mathrm{OC}}$ increased linearly with time. The time for the full reduction of the active content from $\mathrm{Fe}_{2} \mathrm{O}_{3}$ to $\mathrm{Fe}_{3} \mathrm{O}_{4}$ was 2.1 min for the A-RM OC and 2.4 min for the S-RM OC. The Ilmenite OC took 9.3 min to reduce $\mathrm{Fe}_{2} \mathrm{TiO}_{5}$ to $\mathrm{FeTiO}_{3}$, showing a much lower reactivity than the two RM OCs. In Fig. 5(a), steam present in the reducing gas significantly inhibited the reduction of all OCs. Only results with SynP3 (containing 15\% $\mathrm{CO}$ and 30\% steam) are shown for the two RM OCs because the simultaneous increase of CO and steam partial pressures does not affect the OC's reactivity. When compare to the reduction with dry gas (15\% $\mathrm{CO}$ ), the time required for full conversion with wet syngas (SynP3) increased 6-fold for the A-RM OC, 9fold for the S-RM OC, and > 20-fold for the ilmenite OC. Thus the effect of steam is OC-dependent. Interestingly, the A-RM OC performed twice as fast as the S-RM OC when steam was added to the reducing gas. For ilmenite OC, $4 \%$ of transferable oxygen is theoretically available if the reaction precedes according Reaction (3) and (4). With the addition of steam, the transferable oxygen of the ilmenite OC was reduced to $<4 \%$, and the reactivity was strongly dependent on the type of syngas used. The striking decrease in the reactivity of the iron-based OCs can be partially attributed to the reverse oxidation caused by steam. This reaction occurs simultaneously with the OC reduction reaction to slow down the overall reduction rate. In this study, this behavior was explored for better understanding the performance of the solid-fueled PCLC at high steam concentration. 

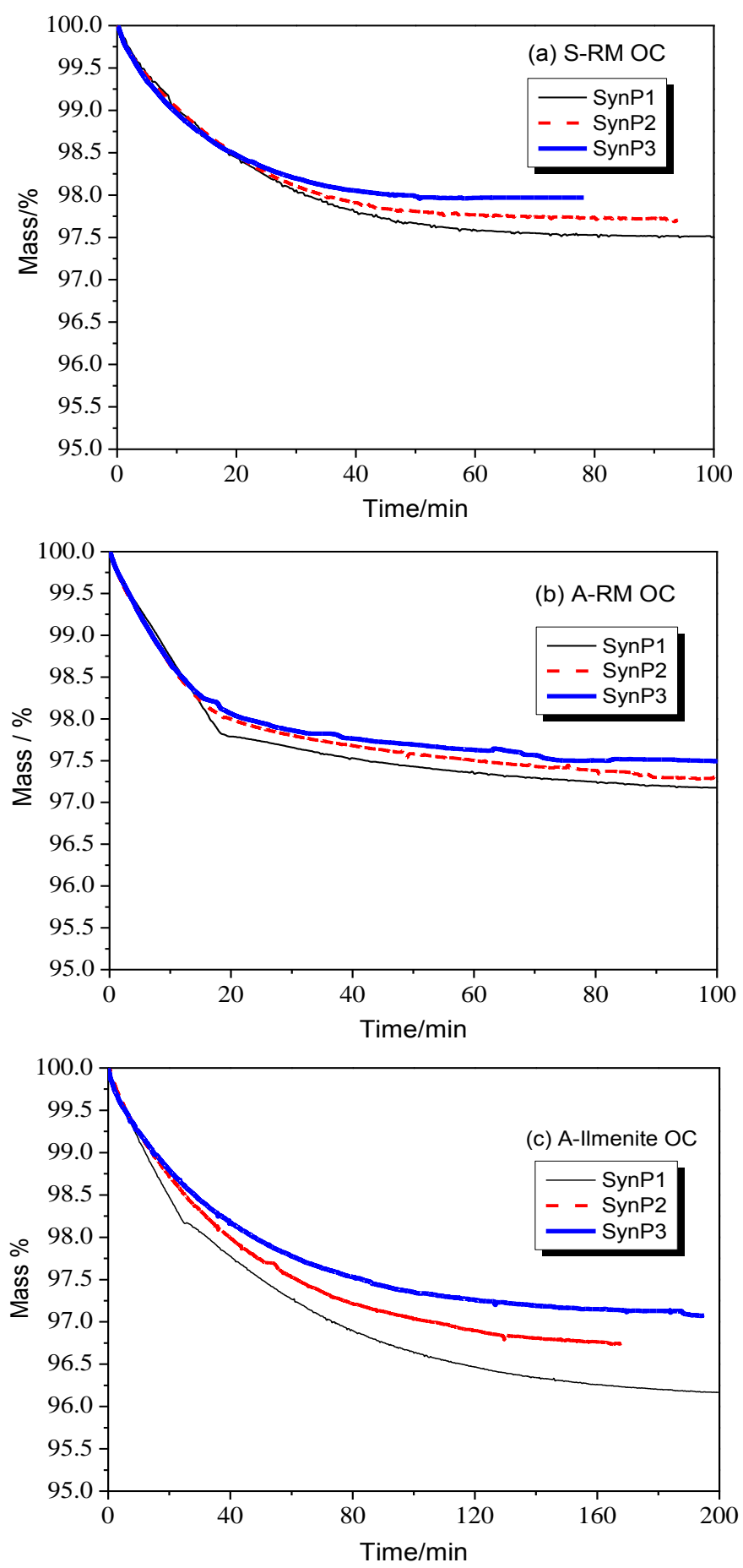

Fig. 4 TGA profiles for the reduction of OCs using different wet syngas $\left(\mathrm{T}=950{ }^{\circ} \mathrm{C}, \mathrm{SynP} 1-5 \% \mathrm{CO}\right.$ and $10 \%$ steam, SynP2 - 10\% CO and 20\% steam, SynP3 - 15\% CO and 30\% steam) 

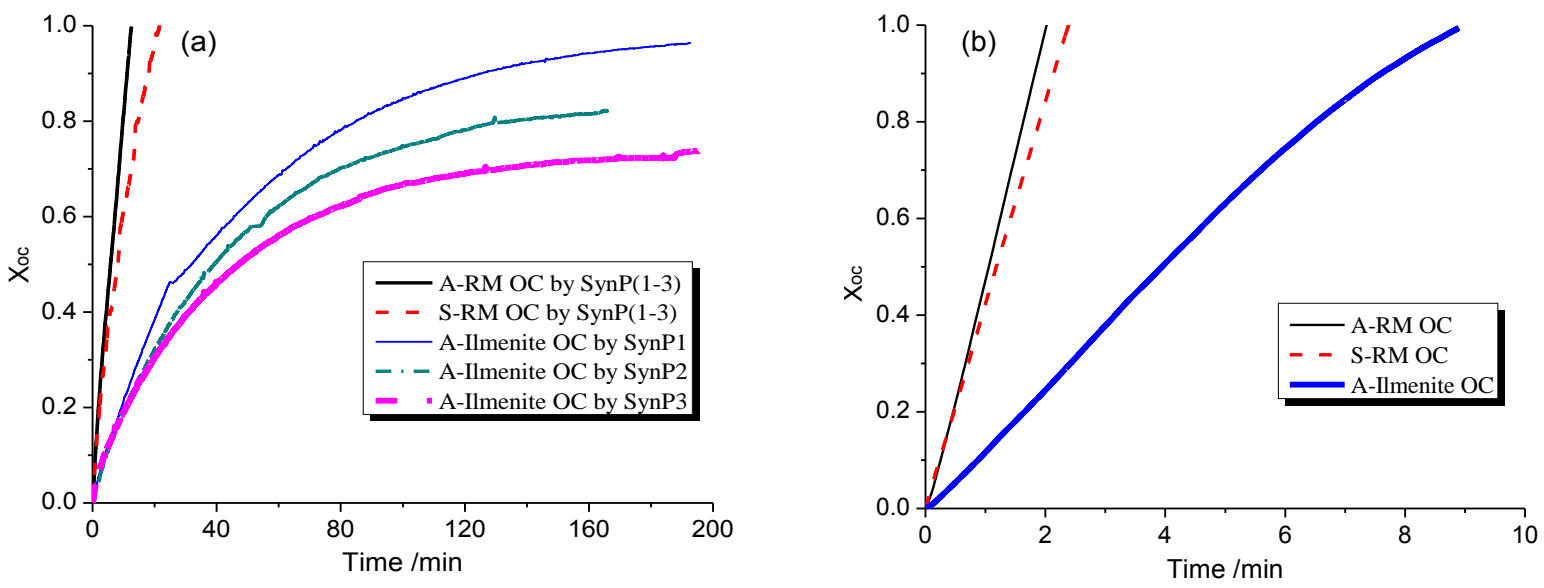

Fig. 5. Reduction reactivity of different OCs (a) with and (b) without steam in the reducing gas

\subsection{Effect of pressure on OC's selectivity}

The selectivity obtained from the fixed-bed reactor reveals detailed information to what extent the wet syngas can be fully oxidized by OC materials. Fig. 6 shows the effect of operational pressure on ironbased OC selectivity. In these figures, the values of $S_{\mathrm{syn}}$ are plotted as a function of $X_{\mathrm{OC}}$. As an example, the dry gas profiles during the reduction of A-RM OC at 1 and 6 bars, and the following oxidation step are shown in S-Fig. 2. Due to thermodynamic limitation and channel flow, the resulting selectivity was consistently lower than $100 \%$. When the reduction was beyond $\mathrm{Fe}_{3} \mathrm{O}_{4}$ or $\mathrm{FeTiO}_{3}$, the value of $S_{\text {syn }}$ declined quickly as $X_{\mathrm{OC}}$ increased further. When two RM OCs were reduced between $\mathrm{Fe}_{2} \mathrm{O}_{3}$ to $\mathrm{Fe}_{3} \mathrm{O}_{4}$ $\left(X_{\mathrm{OC}}<1.0\right)$, the values of $S_{\mathrm{syn}}$ were stable with the changes of $X_{\mathrm{OC}}$ and the operational pressure. Although the two RM OCs possessed different crystalline structures and react differently with wet syngas, the average $S_{\text {syn }}$ was the same (0.995). This value is very close to the thermodynamic equilibrium of the redox pair of $\mathrm{Fe}_{2} \mathrm{O}_{3} / \mathrm{Fe}_{3} \mathrm{O}_{4}$ at $950{ }^{\circ} \mathrm{C}$. The average value of $S_{\text {syn }}$ for the ilmenite OC are lower than RM OCs at all pressures. The highest value of $S_{\mathrm{syn}}$ for the ilmenite OC was 0.971 at 1 bar. As indicated by Fig. 6 (c), the elevated operational pressure shows negative effects on ilmenite OC reactivity. During this time, the maximum value of $X_{\mathrm{OC}}$ corresponding to high selectivity decreased from 1.0 to 0.73 when the operational pressure increased from 1 to 6 bars. It was possible that the OC particle size used in this study may not eliminate the diffusion limitation caused by the dense structure of ilmenite ore.

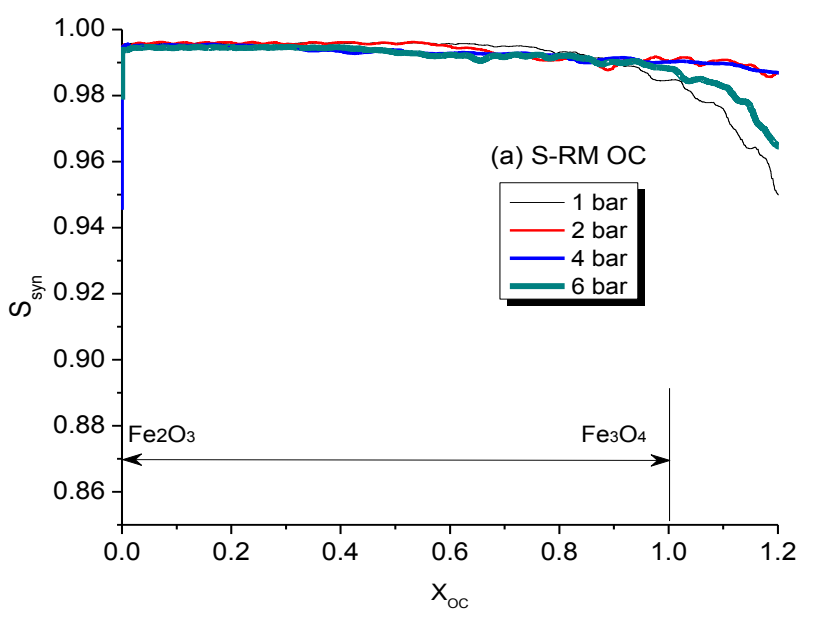



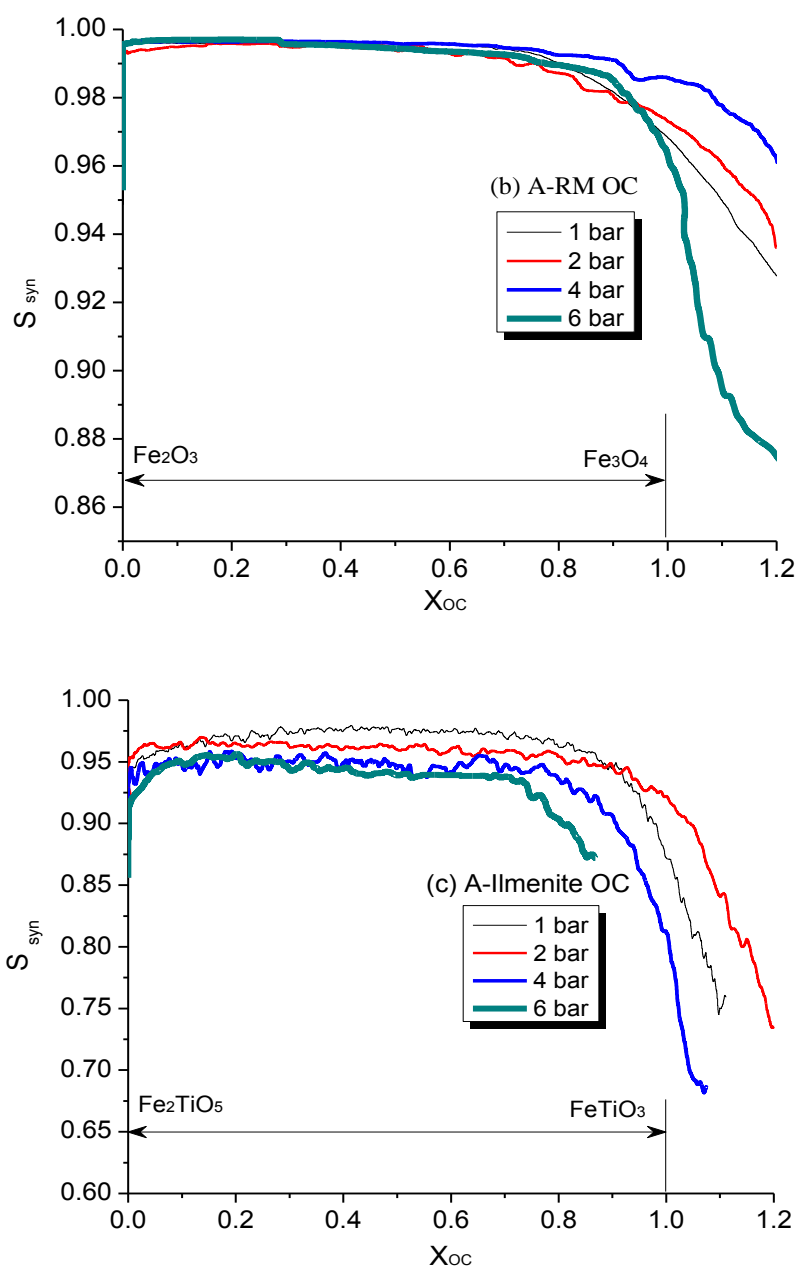

Fig. 6 Effect of operational pressure on the selectivity of different OCs with wet syngas

\subsection{In-situ gasification}

In PCLC experiments, four different solid materials, including three iron-based OCs and fused $\mathrm{Al}_{2} \mathrm{O}_{3}$ particles were used as bed materials, while three different coal chars, PRB, WKY, and EKY, were used as fuels. Reactivity of the coal char is in the following order: PRB > WKY >> EKY. As examples, the drybased gas concentration profiles of CLC experiments using A-RM and PRB char at 1 bar and 6 bars are shown in S-Fig. 3. Due to high reactivity and selectivity of A-RM OC, the CLC experiments at various pressure consisted of high $\mathrm{CO}_{2}$ concentrations and very low combustible gas $\left(\mathrm{H}_{2}\right.$ and $\left.\mathrm{CO}\right)$ concentrations during the reduction period. This behavior suggested that most of the intermediate syngas around the coal char particles were effectively removed with the presence of OC particles. The in-situ gasification improved as operational pressure increased. As shown in S-Fig. 3, the time required for full conversion of char was reduced from $550 \mathrm{~s}$ to $320 \mathrm{~s}$ as the operational pressure increased from 1 bar to 6 bars.

Gasification rates of all fluidized bed experiments were calculated by Eq. (5) and plotted against $X_{\mathrm{c}}$. The results clearly indicated that the OC reactivity and steam partial pressure are the most important parameters that impact in-situ gasification. The use of OCs improves gasification rate through lowered inhibition as $\mathrm{CO}$ and $\mathrm{H}_{2}$ are quickly oxidized by OCs. According to this reaction regime, the PCLC experiments using A-RM OC and fused $\mathrm{Al}_{2} \mathrm{O}_{3}$ particles provide unambiguous boundaries to analyze the 
roles of OCs in the complex reaction system. The in-situ gasification with A-RM OC was totally dominated by the reaction between steam and carbon, and almost free of inhibition effects from $\mathrm{CO}_{2}$ or $\mathrm{H}_{2}$. Because the intermediate syngas was not locally consumed as they were generated, the external gasification with fused $\mathrm{Al}_{2} \mathrm{O}_{3}$ particles represents the char gasification process which experiences the maximum inhibition effect from its syngas products. If OC reactivity fallen between these two OC materials, the gasification process was controlled by both steam-carbon reaction and a reduced inhibition effect. A comparison of gasification behaviors at 1 bar and 6 bars between CLC experiment using A-RM OC and external gasification is presented in Fig. 7. The rate of the external gasification at both ambient and elevated pressure increased linearly with $X_{\mathrm{C}}$ (under steady reaction condition). The uninhabited insitu gasification with A-RM OC increased the rate of char gasification rapidly with carbon conversion. Fig. 8 demonstrates the EKY char gasification behaviors in the CLC experiments with ilmenite OC and that of external gasification. Because of the low reactivity of both ilmenite OC and coal char, the CLC experiments resulted in little improvement in gasification, and showed similar gasification behaviors as the external gasification at various pressures.

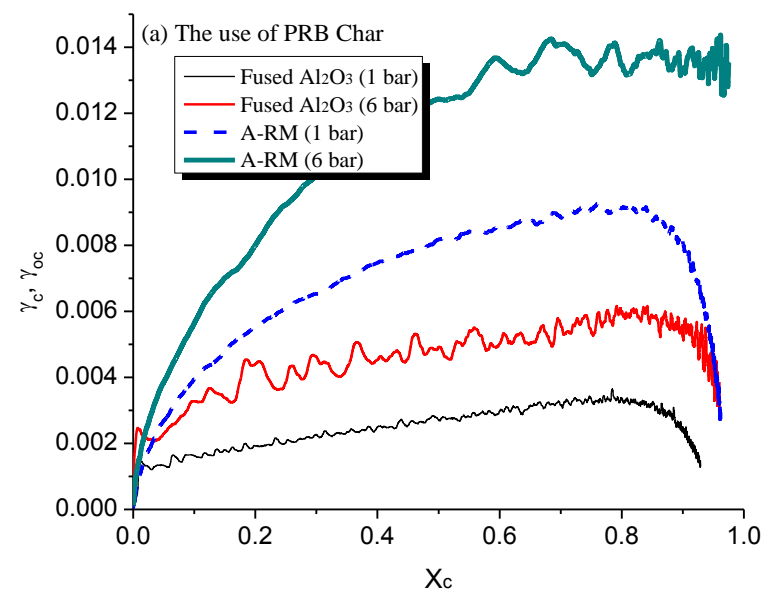

Fig. 7 Instantaneous rates of char gasification of CLC with A-RM OC and external gasification with fused $\mathrm{Al}_{2} \mathrm{O}_{3}$ particles when PRB char was used as fuel.

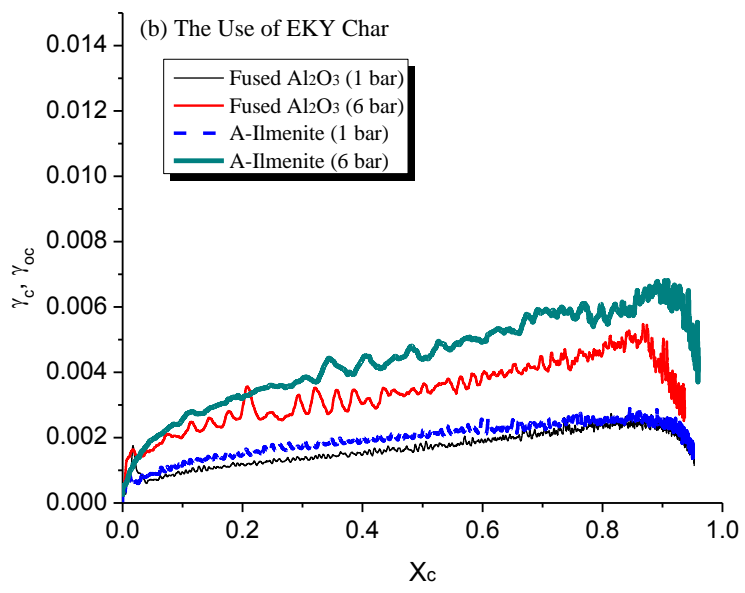

Fig. 8 Instantaneous rates of char gasification of CLC with ilmenite OC and external gasification with fused $\mathrm{Al}_{2} \mathrm{O}_{3}$ particles when EKY char was used as fuel.

To better understand and identify these major variables affecting gasification, the average instantaneous gasification rates in CLC and external gasification, $r_{\mathrm{c}}$ were plotted against operational pressure for different coal chars, as shown in Fig 9. To avoid mathematical errors introduced at the beginning and the end of reaction [15], only the steady-state reaction condition $\left(0.1<X_{\mathrm{C}}<0.8\right)$ was used to calculate the average gasification rate. Some general conclusions can be drawn from Fig. 9. The values of $\overline{r_{\mathrm{c}}}$ for both CLC and external gasification increased linearly with the operational pressure despite the type of coal char used. When the same OCs and pressure were used, the reaction rate of active coal char was consistently higher than less active coal char. For a given coal char and operational pressure, the value of $\bar{r}_{\mathrm{c}}$ strictly followed the same order of OC's reactivity tested in TGA, A-RM > S-RM> Ilmenite> fused $\mathrm{Al}_{2} \mathrm{O}_{3}$ particles.

The reaction of the solid-fueled CLC is operated at intermediate temperature (800-1050 $\left.{ }^{\circ} \mathrm{C}\right)$ at which char gasification with steam is kinetically controlled (Regime I). In this study, coal char gasification with 
different solids (OCs and fused $\mathrm{Al}_{2} \mathrm{O}_{3}$ particles) can be classified into this regime which follows a Langmuri-Hinshewood (LH) reaction mechanism [13, 37-38]

$$
\begin{aligned}
& \mathrm{C}_{f}+\mathrm{H}_{2} \mathrm{O} \underset{k 2}{\stackrel{k 1}{\Leftrightarrow}} \mathrm{C}(\mathrm{O})+\mathrm{H}_{2} \\
& \mathrm{C}(\mathrm{O}) \stackrel{k 3}{\rightarrow} \mathrm{CO}
\end{aligned}
$$

Here $\mathrm{C}_{f}$ is a free carbon site, and $\mathrm{C}(\mathrm{O})$ is the surface complex which is converted to gaseous phase of carbon monoxide $\mathrm{CO}$ via Eq. (11). $\mathrm{H}_{2}$ and $\mathrm{CO}$ are the gasification inhibitors, but the reaction appears to be coal char-dependent [13]. The presence of hydrogen inhibits the steam-carbon reaction by two possible pathways:

$$
\begin{gathered}
\mathrm{C}_{\mathrm{f}}+\mathrm{H}_{2} \stackrel{k 4}{\leftrightarrow} \mathrm{C}\left(\mathrm{H}_{2}\right) \\
\mathrm{C}_{\mathrm{f}}+0.5 \mathrm{H}_{2} \stackrel{k 5}{\leftrightarrow} \mathrm{C}(\mathrm{H})
\end{gathered}
$$

Due to the complexity of the LH mechanism, the present results do not exactly identify which gas product $\left(\mathrm{CO}\right.$ or $\left.\mathrm{H}_{2}\right)$ is the primary gasification inhibitor in the PCLC experiments. Therefore, it is difficult to develop a rate equation to describe the role of the OCs. However, the results in Fig. 9 qualify the limitation of using OCs and elevated steam partial pressure for the complex reaction system. In Fig. 9, Line 1 (in zone II) represents the dependence of the rate of external gasification on the steam partial pressure (half of the total pressure), while Line 2 (in zone II) defines the dependence of the rate of "real" in-situ gasification (free of gasification inhibition) on the steam partial pressure. For a given fuel char, the PCLC with any OCs will be operated at a rate between these two boundaries. The improvement in gasification over Line 1 depends on the OC performance and the steam partial pressure. It is worth noting that the "real" in-situ gasification exhibits higher increasing rate as the steam partial pressure increases compared to the external gasification. Therefore, a higher potential for promoting char gasification (the differences between Line 1 and Line 2) can be achieved at a higher steam partial pressure. It can be also found that the potential for promoting char gasification in CLC is related to the coal char reactivity. For the "real" in-situ gasification, the reactions given by Reaction (10)-(11) are the vital limiting-steps of the overall reaction. Therefore, the potential for promoting char gasification can be improved by these measures that could increase the kinetics of Reaction (10)-(11).

Under the realistic conditions, reasonable operational pressure for PCLC-CC should be in the range of 12 to 30 bars, which is higher than the pressure level tested in this study. Unfortunately, there were some uncertainties to directly predict the PCLC gasification behavior via the extrapolation from the present results to higher pressure (such as zone III in Fig. 9). At higher pressure, the surface saturation of steam on the char surface, kinetics of the OC reduction, and the diffusion process may play very different roles. So, reliable measurements at higher pressure are required for more accurate understanding the reaction models. 

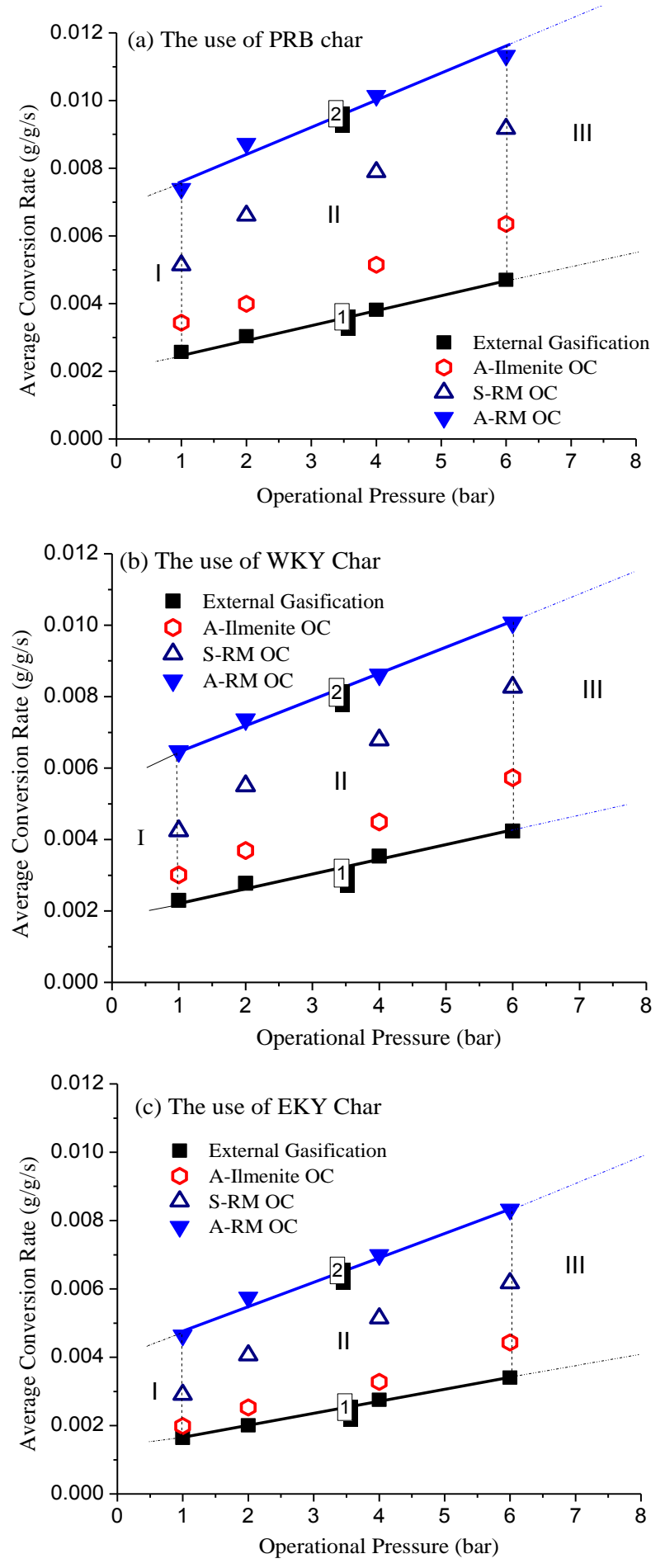

Fig. 9 Average gasification rate of PCLC and external gasification at various pressures.

\subsection{Effects pressure and OC on Water-Gas-Shift reaction}

Fig. 10 illustrates the catalytic function of iron-based OC for the WGSR in PCLC experiments. Here, only results using PRB char are shown because the value of $J$ is little relevant with the type of coal char. The results for external gasification with fused $\mathrm{Al}_{2} \mathrm{O}_{3}$ particles defined the lower limit, while the equilibrium 
constant of $W G S R, K_{\text {eq, } 950}=0.68$ is used as the upper limit. Compared to fused $\mathrm{Al}_{2} \mathrm{O}_{3}$ particles, ilmenite OC did not promote $W G S R$, and S-RM OC showed a weak promotion for WGSR. Conversely, A-RM OC exhibited strong promotion with the value of $J$ very close to the equilibrium constant. The value of $J$ slightly decreased from 0.57 at 1 bar to 0.48 at 6 bars. Considering the short residence time, the WGSR with A-RM OC as catalyst proceeded very quickly towards the equilibrium conditions in the bed zone. The strong catalytic function was possibly provided by the free $\mathrm{Fe}_{3} \mathrm{O}_{4}$ phase in the reduced A-RM OC, which is a well-known catalyst for the reaction.

The catalyzed WGSR in the bed zone of the FR plays important roles for improving char gasification. The strongly catalyzed WGSR among the intermediate syngas can significantly lower CO content while increasing the concentration of $\mathrm{H}_{2}$. This allows more $\mathrm{H}_{2}$ to react with the OCs at a higher rate, and in turn, the quick consumption of gasification inhibitors increases the combustion efficiency and in-situ gasification rate. Therefore, the strongly catalyzed WGSR partially explains the higher reactivity of A-RM OC with coal char compared to S-RM OC.

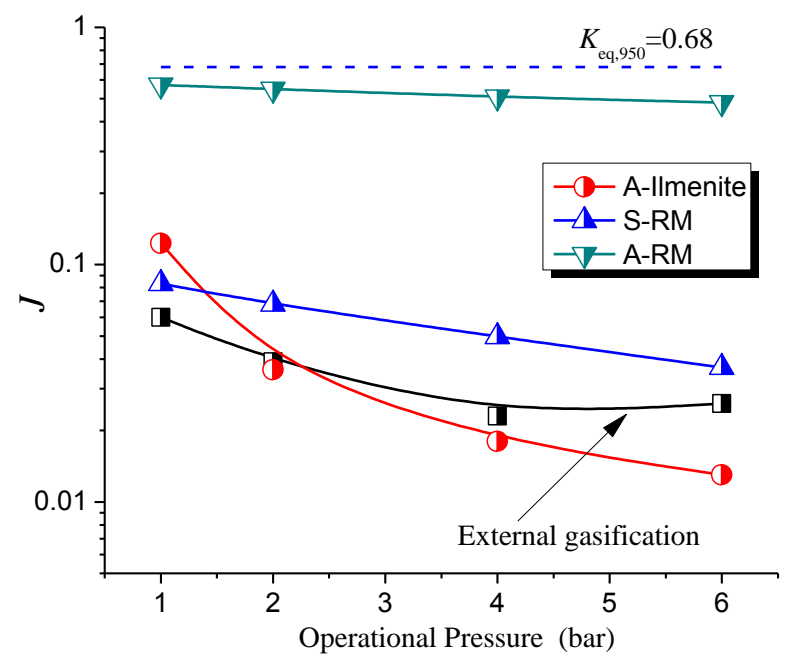

Fig. 10 The extent of $W G S R$ for the PRB char-fueled PCLC using different OCs (the equilibrium constant of $W G S R$ at $950{ }^{\circ} \mathrm{C}$ is calculated by $\log K_{e q}=-2.4198+0.0003855 T+\frac{2180.6}{T}$ )

\subsection{Combustion efficiency}

The concentrations of $\mathrm{CO}$ and $\mathrm{H}_{2}$ in the gas products of CLC should be as low as possible. Otherwise gas fuel recovery or a purification process is needed prior to $\mathrm{CO}_{2}$ sequestration. As an example, Fig. 11 shows the combustion efficiency of the WKY char-fueled PCLC, where the instantaneous value of $\eta_{\text {syn }}$ is plotted against $X_{\mathrm{OC}}$. Under stable reaction conditions, $\eta_{\mathrm{syn}}$ of the two RM OCs was high and stable, and unaffected by the operational pressure. The values of $\eta_{\text {syn }}$ for ilmenite $\mathrm{OC}$ decreased as the operational pressure increased. Table 3-5 lists the average combustion efficiencies $\left(\eta_{\mathrm{syn}}^{-}\right)$of the PCLC experiments and the average selectivity $\left(\bar{S}_{\text {syn }}\right)$ obtained in the fixed-bed reactor for A-RM, S-RM and ilmenite OCs. The steadystate reaction conditions, i.e. $0.1<X_{\mathrm{C}}<0.8$ and $0<X_{\mathrm{OC}}<0.9$ were used to determine the values of $\bar{\eta}_{\text {syn }}$ and $\bar{S}_{\text {syn }}^{-}$ The thermodynamics shows that the equilibrium constants for the reduction of $\mathrm{Fe}_{2} \mathrm{O}_{3}$ to $\mathrm{Fe}_{3} \mathrm{O}_{4}$ with $\mathrm{H}_{2}$ and $\mathrm{CO}, K_{\mathrm{eq}}=\left(C_{\mathrm{H} 2 \mathrm{O}} / C_{\mathrm{H} 2}\right)$ and $K_{\mathrm{eq}}=\left(C_{\mathrm{CO} 2} / C_{\mathrm{CO}}\right)$ are approximately $10^{5}$ at $950{ }^{\circ} \mathrm{C}$ [1], suggesting a complete conversion of syngas to $\mathrm{H}_{2} \mathrm{O}$ and $\mathrm{CO}_{2}$. The redox pair of $\mathrm{Fe}_{2} \mathrm{TiO}_{5} / \mathrm{FeTiO}_{3}$ is also favorable to convert fuel gas to $\mathrm{H}_{2} \mathrm{O}$ and $\mathrm{CO}_{2}$ with a maximum conversion > 99.7\%. According to Eq. (1)-(4), the increase in total 
pressure would not affect equilibrium constant or selectivity. In the solid-fueled PCLC, the reaction between coal char and OCs occurs via the phase transfer of intermediate gas. Except for the thermodynamic limitation and OC reactivity, the imperfect gas phase transfer between char and OCs (including intermediate syngas, product gas and steam), and char gasification at the upper part of reactor, may lead to some amount of unconverted gas exiting the FR with the fluidization gas. The OC selectivity from the fixed-bed experiments are more ideal combustion efficiency because the syngas in these experiments had enough time to react with OCs. Therefore, the order of $\bar{\eta}_{\text {syn }}<\bar{S}_{\text {syn }}<S_{\text {thermal }}$ is strictly followed for all three OCs used. Here, $S_{\text {thermal }}$ is the OC selectivity determined by thermodynamics.

The calculated values of $\bar{S}_{\text {syn }}$ for the A-RM and S-RM OCs are slightly less than the thermodynamic equilibrium of $\mathrm{Fe}_{2} \mathrm{O}_{3} / \mathrm{Fe}_{3} \mathrm{O}_{4}$, and independent of operational pressure. In the CLC experiments using ARM OC, 0.97-0.98 of $\bar{\eta}_{\text {syn }}$ was achieved, and the value of $\bar{\eta}_{\text {syn }}$ was evidently independent of operational pressure and the type of coal char. Similar behaviors were observed during the CLC experiments using SRM OC, but the value of $\bar{\eta}_{\text {syn }}$ was fixed between 0.93-0.94. For the A-RM OC, the minor difference between $\bar{\eta}_{\text {syn }}$ and $\bar{S}_{\text {syn }}(1.7-2.4 \%$ points) suggests that the flow pattern used for the FR reaction system could ensure that char gasification took place throughout the fluidized-bed zone, and that gas phase diffusion between the two different particles (char and OC) were not the limiting-step. The value of $\left(\bar{S}_{\mathrm{syn}}-\bar{\eta}_{\mathrm{syn}}\right)$ for S-RM OC was increased to $5.6-6.4 \%$ points. Obviously, the increase of $\left(\bar{S}_{\mathrm{syn}}-\bar{\eta}_{\mathrm{syn}}\right)$ is due to the relatively lower reactivity of the S-RM OC, and the intermediate syngas did not have enough time to react with OCs before they exited the reactor.

The value of $\bar{S}_{\text {syn }}$ for ilmenite OCs was lower than RM OCs, and strongly pressure-dependent. Accordingly, $\bar{\eta}_{\text {syn }}$ of ilmenite OCs declined with operational pressure, but was independent of the type of coal char. If the values of $\bar{S}_{\text {syn }}$ at different pressures were used as the upper limit to evaluate the intermediate syngas conversion of PCLC, the difference between $\bar{\eta}_{\mathrm{syn}}$ and $\bar{S}_{\mathrm{syn}}$ are 3.0-5.0\% points when the operational pressure was between 1-4 bars. But at 6 bars, $\left(\bar{S}_{\mathrm{syn}}-\bar{\eta}_{\mathrm{syn}}\right)$ was abruptly enlarged to $8.2-10 \%$ points. 

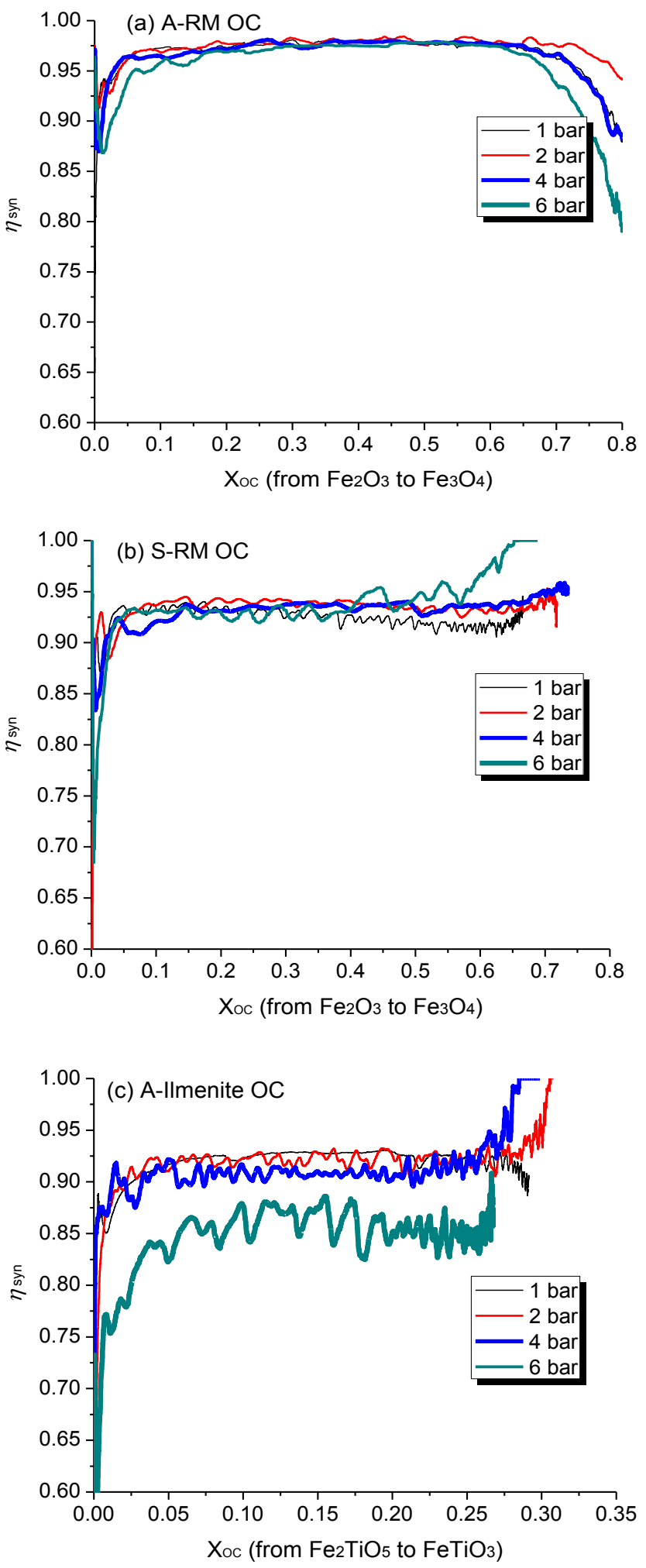

Fig. 11 Effect of operational pressure on combustion efficiency of the WKY char-fueled PCLC 
Table 3

Average combustion efficiency of PCLC and selectivity of A-RM OC

\begin{tabular}{ccccc}
\hline \multirow{2}{*}{ Pressure (bar) } & Selectivity/ $\bar{S}_{\text {syn }}$ & \multicolumn{3}{c}{$\bar{\eta}_{\text {syn }}$ of PCLC } \\
\cline { 3 - 5 } & & PRB Char & EKY Char & WKY Char \\
\hline 1 & 0.995 & 0.979 & 0.973 & 0.972 \\
2 & 0.994 & 0.980 & 0.975 & 0.973 \\
4 & 0.996 & 0.977 & 0.972 & 0.973 \\
6 & 0.995 & 0.975 & 0.969 & 0.963 \\
\hline
\end{tabular}

Table 4

Average combustion efficiency of PCLC and selectivity of S-RM OC

\begin{tabular}{ccccc}
\hline \multirow{2}{*}{ Pressure (bar) } & \multirow{2}{*}{ Selectivity/ $\bar{S}_{\text {syn }}$} & \multicolumn{3}{c}{$\bar{\eta}_{\text {syn }}$ of PCLC } \\
\cline { 3 - 5 } & & PRB Char & EKY Char & WKY Char \\
\hline 1 & 0.996 & 0.928 & 0.935 & 0.924 \\
2 & 0.995 & 0.936 & 0.937 & 0.938 \\
4 & 0.994 & 0.928 & 0.941 & 0.930 \\
6 & 0.996 & 0.942 & 0.944 & 0.933 \\
\hline
\end{tabular}

Table 5

Average combustion efficiency of PCLC and selectivity of Ilmenite OC

\begin{tabular}{ccccc}
\hline \multirow{2}{*}{ Pressure (bar) } & Selectivity/ $\bar{S}_{\text {syn }}$ & \multicolumn{3}{c}{$\bar{\eta}_{\text {syn }}$ of PCLC } \\
\cline { 3 - 5 } & & PRB Char & EKY Char & WKY Char \\
\hline 1 & 0.971 & 0.931 & 0.923 & 0.927 \\
2 & 0.964 & 0.913 & 0.920 & 0.914 \\
4 & 0.948 & 0.911 & 0.918 & 0.900 \\
6 & 0.944 & 0.862 & 0.846 & 0.842 \\
\hline
\end{tabular}

\section{Conclusion}

This study demonstrated experimentally the effects of steam partial pressure, coal char reactivity and different iron-based OC's performances on the solid-fueled PCLC. The main conclusions can be drawn as follows:

(1) The OC reactivity determined by TGA showed that steam present in syngas significantly inhibits the reduction rate of iron-based OCs, but this effect depends on the OC material. The simultaneous increasing partial pressure of reducing gas and steam does not affect the reactivity of Red Mud OCs. However, this seems to reduce the lattice oxygen transferring rate of activated ilmenite OC.

(2) The FR of solid-fueled PCLC unit is a complex reaction system, where the reaction between coal char and OCs occurs via the phase transfer of intermediate gas. The experiment operated at bubbling fluidization regime suggested that the phase transfer of intermediate syngas is not the limiting-step for the FR reaction system. The in-situ gasification follows Langmuri-Hinshewood reaction regime, thus the OC's reactivity and steam partial pressure are two major aspects that could significantly impact in-situ gasification. The average in-situ gasification rate increases linearly with the steam partial pressure (in the 
range of 0.5-3.0 bars) for all OCs, and the value strictly follows the same order of OC's reactivity, A-RM > $\mathrm{S}-\mathrm{RM}>$ Ilmenite> fused $\mathrm{Al}_{2} \mathrm{O}_{3}$ particles. The PCLC experiment using the best OC, A-RM, appears to eliminate the gasification inhibition from $\mathrm{CO}$ or $\mathrm{H}_{2}$.

(3) The combustion efficiencies of the solid-fueled PCLC are closely related to the OC's selectivity and reactivity. When using Red Mud OCs, the average combustion efficiencies are very high and unaffected by the type of coal char and steam partial pressure. The activated ilmenite OC is less favorable for intermediate syngas conversion at elevated pressure due to the simultaneous reduction in OC selectivity and reactivity at these conditions.

(4) The WGSR in the bed zone of the FR may be catalyzed by the reduced OCs. Due to strong catalytic function of A-RM OC for WGSR, the final gas product was very close to the equilibrium condition. The catalyzed WGSR allows more $\mathrm{H}_{2}$ to react with OCs at a higher rate. As a result, the in-situ gasification rate could be increased with the lowered gasification inhibitions.

\section{Acknowledgement}

The authors thank the US Department of Energy (US-DOE) for its financial support (DE-FE0025098) as well as the Kentucky Energy and Environment Cabinet Department for Energy (Development and Independence Grant Program), and Energy Research the Carbon Management Research Group consortium at the University of Kentucky Center for Applied Energy (UKy-CAER), including American Electric Power, Duke Energy, Electric Power Research Institute, L\&GE and KU Service Company.

\section{References}

[1] Juan A, Alberto A, Francisco GL, Pilar G, Luis FD. Progress in chemical-looping combustion and reforming technologies. Prog. Energy Combust. Sci. 2012; 38(2): 215-282.

[2] Carl L, Tobias M, Anders L. Long-term integrity testing of spray-dried particles in a 10-kW chemical-looping combustor using natural gas as fuel. Fuel 2009; 88: 2083-2096.

[3] Philipp K, Johannes BN, Tobias P, Hermann H. Comparison of two Ni-based oxygen carriers for chemical looping combustion of natural gas in $140 \mathrm{~kW}$ continuous looping operation. Ind. Eng. Chem. Res. 2009; 48: 5542-5547.

[4] Stefan P, Karl M, Stefan K, et al, Chemical-looping combustion of raw syngas from biomass steam gasificationcoupled operation of two dual fluidized bed pilot plants. Fuel 2014; 127: 178-185.

[5] Stainton H, Ginet A, Surla K, Hoteit A. Experimental investigation of CLC coal combustion with nickel based particles in a fluidized bed. Fuel 2012; 101: 205-214.

[6] Hyung RK, Dawei W, Liang Z, et al. Coal direct chemical looping combustion process: Design and operation of a 25-kWth sub-pilot unit. Fuel 2013; 108: 370-384.

[7] Carl L, Anders L, Ana, Erik. Chemical-looping combustion of solid fuels - Operation in a $10 \mathrm{~kW}$ unit with two fuels, above-bed and in-bed fuel feed and two oxygen carriers, manganese ore and ilmenite. Fuel 2012; 102: $808-822$.

[8] Andrew T, Samuel B, Mandar VK, et al. Iron-based syngas chemical looping process and coal-direct chemical looping process development at Ohio State University. Appl Energy 2014; 113: 1836-1845.

[9] Nicolas B, Anders L. The use of petroleum coke as fuel in a $10 \mathrm{~kW}_{\text {th }}$ chemical-looping combustor. Int $\mathrm{J}$ Greenhouse Gas Control 2008; 2:169-179.

[10] Fanxing L, Liang Z, Liang-Shih F. Biomass direct chemical looping process: Process simulation. Fuel 2010; 89: 3773-3784.

[11] Haiming G, Laihong S, Jun X, et al. Chemical Looping Combustion of biomass/coal with natural iron ore as oxygen carrier in a continuous reactor. Energy Fuels 2011; 25: 446-455.

[12] Ana C, Alberto A, Luis FD, et al. Prompt considerations on the design of chemical-looping combustion of coal for experimental tests. Fuel 2012; 97: 219-232.

[13] Martin K, Henrik L, Tobias M, Anders L. Gasification inhibition in chemical-looping combustion with solid fuel. Combust. Flame 2011; 158(3): 393-400. 
[14] Berguerand N, Anders L. Design and operation of a $10 \mathrm{~kW}_{\text {th }}$ chemical-looping combustor for solid fuelsTesting with South African coal. Fuel 2008; 87(12): 2713-2726.

[15] Pontus M. Design, modeling and operation of a $100 \mathrm{~kW}_{\text {th }}$ chemical-looping combustor for solid fuel. Thesis for the degree of doctor philosophy, Chalmers University of Technology, 2012.

[16] Herbert EA. Gregory B. John HC et al. Hybrid combustion-gasification Chemical Looping coal power technology development- Phase III - final report to US DOE, 2008.

[17] Bayham SC. Hyung RK, Dawei W, Andrew T, Liang Z, et al. Iron-based coal direct chemical looping combustion process: 200-h continuous operation of a 25-kWth sub-pilot unit. Energy Fuels 2013; 27:1347-1356.

[18] Peter O, Jochen S, Bernd E. Chemical-looping combustion of hard coal: auto thermal operation of a $1 \mathrm{MW}_{\text {th }}$ pilot plant. Proceedings of the $40_{\text {th }}$ International Technical Conference on Clean Coal \& Fuel Systems, 2015; Sheraton Sand Key Clearwater, Florida, USA.

[19]455MWe CLC boiler/plant feasibility report and recommendations for the next step. 2005; http://www.encapco2.org.

[20] Anders L, Bo L. A $1000 \mathrm{MW}_{\text {th }}$ boiler for chemical-looping combustion of solid fuels-discussion of design and costs. Appl Energy 2015; 157(1):457-487.

[21] Guidance for NETL's Oxy-combustion R\&D Program: Chemical Looping Combustion reference plant designs and sensitivity studies. DOE/NETL, 2014.

[22] Hamers HP, Romano MC, Spallina V. et al. Comparison on process efficiency for CLC of syngas operated in packed bed and fluidized bed reactors. Int J Greenhouse Gas Control 2014; 28: 65-78.

[23]Zhen F, Liangyong C, Fang L, Jinhua B, Heather N, Kunlei L. Coal based Pressurized Chemical Looping Combustion Combined Cycle -Process development and analysis, $4^{\text {th }}$ International Conference on Chemical Looping. 2016; Nanjing, China.

[24] Rui X, Qilei S, Shuai Z, et al, Pressurized Chemical-Looping Combustion of Chinese bituminous coal: cyclic performance and characterization of iron ore-based oxygen carrier. Energy Fuels 2010; 24: 1449-1463.

[25] Rui X, Liangyong C, Chiranjib S, Shuai Z, Sankar B. Pressurized chemical-looping combustion of coal using an iron ore as oxygen carrier in a pilot-scale unit. Int J Greenhouse Gas Control 2012; 10: 363-373.

[26] Hamers HP, Gallucci F, Williams G, Annaland MS. Experimental demonstration of CLC and the pressure effect in packed bed reactors using $\mathrm{NiO} / \mathrm{CaAl}_{2} \mathrm{O}_{4}$ as oxygen carrier. Fuel 2015; 159: 828-836.

[27] Hamers HP, Gallucci F, Williams G, Cobden PD, Annaland MS. Reactivity of oxygen carriers for ChemicalLooping Combustion in packed bed reactors under pressurized conditions. Energy Fuels 2015; 29: 2656-2663.

[28] Francisco GL, Juan A, Luis FD, Pilar G, Alberto A. Effect of pressure on the behavior of copper-, iron-, and nickel-based oxygen carriers for Chemical-Looping Combustion. Energy Fuels 2006; 20: 26-33.

[29] Oscar N, Lu H, Zhiquan Z, George MB. High-Pressure Chemical-Looping of methane and synthesis gas with $\mathrm{Ni}$ and $\mathrm{Cu}$ oxygen carriers. Energy Fuels 2016; 30: 504-514.

[30] Niranjani D, Ankita M, Lang Q, Liang-shin. F. High-pressure redox behavior of iron-oxide-based oxygen carriers for syngas generation from methane. Energy Fuels 2015; 29:1469-1478.

[31] Henrik L, Anders L, Marcus J, et al. The use of ilmenite as oxygen carrier in Chemical Looping Combustion. Ind. Eng. Chem. Res. 2008; 86(9): 1017-1026.

[32] Henrik L, Mattisson T, Anders L. Solid fuels in chemical-looping combustion. Int J Greenhouse Gas Control 2008; 2:180-193.

[33] Alberto A, Adánez J., Luis FD, García-Labiano F, Gayán P. Behavior of ilmenite as oxygen carrier in chemicallooping combustion. Fuel Process. Technol. 2012; 94(1):_101-112.

[34] Liangyong C, Yi Z, Fang L, Kunlei L. Development of a cost-effective oxygen carrier from red mud for coalfueled chemical-looping combustion. Energy Fuels 2015; 29: 305-313.

[35] Liangyong C, Jinhua B, Liang K, Megan C, Heather N, Zhen F, Kunlei L. The direct solid-solid reaction between coal char and iron-based oxygen carrier and its contribution to solid-fueled chemical looping combustion. Applied Energy 2016; 184 (15): 9-18.

[36] Daizo K, Octave L. Fluidization Engineer, Second Edition, 1991; 61-94.

[37] Daniesl GR, Elizabeth MH, David J H, John FS. Kinetics of char gasification with $\mathrm{CO}_{2}$ under Regime II conditions: Effects of temperature, reactant and total pressure. Energy Fuels 2010; 24(10): 5300-5308.

[38] Rui Z, Qin H W, Zhongyang L, et al. Competition and inhibition effects during coal char gasification in the mixture of $\mathrm{H}_{2} \mathrm{O}$ and $\mathrm{CO}_{2}$. Energy Fuels 2013; 27: 5107-5115. 